Nilo André Bernardi Filho

\title{
SUBSÍDIOS BIBLIOGRÁFICOS PARA UTILIZAÇÃO DE LIXÃO DESATIVADO PARA DISPOSIÇÃO FINAL DE RESÍDUOS SÓLIDOS GERADOS NO SETOR CALÇADISTA DO MUNICÍPIO DE JAÚ-SP
}

\begin{abstract}
Dissertação apresentada à Escola de Engenharia de São Carlos da Universidade de São Paulo, como parte dos requisitos para obtenção do título de Mestre em Ciências da Engenharia Ambiental.
\end{abstract}

Orientador: Prof. Assoc. Valdir Schalch 